\title{
Influence of Electromagnetic Fields on Prooxidant/Antioxidant Balance in Rat Liver
}

\author{
Karolina Sieroń-Stołtny ${ }^{1}$, Jarosław Pasek ${ }^{2,3 *}$, \\ Grzegorz Cieślar ${ }^{2}$, Aleksander Sieroń2

\begin{abstract}
${ }^{1}$ Department of Physical Medicine, School of Health Sciences in Katowice, Medical University of Silesia in Katowice, Medyków St. 12, 40-752 Katowice, Poland

${ }^{2}$ Department of Internal Medicine, Angiology and Physical Medicine,

School of Medicine with the Division of Dentistry in Zabrze, Medical University of Silesia in Katowice, Stefana Batorego St. 15, 41-902 Bytom, Poland

${ }^{3}$ Institute of Physical Education, Tourism and Physiotherapy, Academy of Jan Długosz, Armii Krajowej St. 13/15, 41-200 Częstochowa, Poland
\end{abstract}

Received: 8 April 2016

Accepted: 18 August 2016

\begin{abstract}
The potential health consequences of common exposure of human organisms to high-voltage industrial frequency and radio-frequency electromagnetic fields have not yet been completely recognized. The aim of this study was to evaluate the impact of a $50 \mathrm{~Hz}$ electromagnetic field generated by high-voltage alternating electric current transmission lines, a $900 \mathrm{MHz}$ electromagnetic field emitted by mobile phones, and simultaneous exposure to those forms of electromagnetic fields on prooxidant and antioxidant processes in the liver tissue of 40 male rats randomly divided into three experimental groups exposed to different forms of electromagnetic fields and a control sham-exposed one. After completing 28 daily exposures in obtained liver tissue homogenates we determined the contents of markers of prooxidant processes (total oxidant capacity and malone dialdehyde), as well as activity of selected antioxidant enzymes (superoxide dismutase, its isoenzymes $\mathrm{Cu}, \mathrm{Zn}$-SOD and Mn-SOD, catalase and glutathione peroxidase). Moreover, cell ultrastructures in specimens from liver samples were examined under an electron microscope. A four-week exposure to a high-voltage $50 \mathrm{~Hz}$ electromagnetic field did not affect the prooxidant/antioxidant balance in the liver tissue of rats, while exposure to the radiofrequency electromagnetic field emitted by a mobile phone and simultaneous exposure to both forms of electromagnetic field significantly inhibited the intensity of prooxidant processes and decreased the activity of antioxidant enzymes in liver tissue, especially in the case of simultaneous action of both fields - probably due to their excessive use for restoring
\end{abstract}

*e-mail: jarus_tomus@o2.pl 
prooxidant/antioxidant balance without causing any structural changes in liver cells visible in an electron microscope.

Keywords: electromagnetic fields, high-voltage alternating electric current transmission lines, mobile phones, prooxidant/antioxidant balance, oxidative stress

\section{Introduction}

Despite commonplace use of electrical equipment that generates $50 \mathrm{~Hz}$ electromagnetic fields, as well mobile phones that emit radio-frequency electromagnetic fields, the health consequences of exposure of human organisms to those fields have not been fully recognized. And today it is common for humans to be exposed to both fields at the same time. The lack of comprehensive knowledge concerning biological consequences of exposure to electromagnetic fields is the cause of anxiety in many communities around the world, as to the possible harmful influence of that exposure on human health.

There are only a few reports concerning the impact of $50 \mathrm{~Hz}$ electromagnetic fields and radio-frequency electromagnetic fields generated by base transceiver stations (BTS) - as well as mobile phones - on alimentary tract organs [1-2].

It is assumed that electromagnetic fields used in mobile telephone systems may influence the human body by way of two different mechanisms. The first is the influence of electromagnetic fields generated by BTS (not being in direct contact with the human body), whereas the second effect is connected with the influence of electromagnetic fields emitted by mobile phones that affect the body directly. Both those factors interfere, causing cumulative influence of electromagnetic field energy [3-4]. Nevertheless, the research carried out so far denies the occurrence of biological effects dependent on physical modulation of electromagnetic fields [5-6].

Among the unrecognized consequences of exposure of living organisms to electromagnetic fields one can include the impact of those fields upon the pro- and antioxidant status of digestive system organs.

A vital part of homeostasis is the maintenance of the balance of pro- and anti-oxidant systems within the body. Many experimental studies have confirmed that electromagnetic fields with various physical parameters could intensify the generation of reactive oxygen species (ROS) with subsequent disturbances of a balance between an intensity of oxidant processes and capacity of antioxidant defense system, depending on the activity of antioxidant enzymes and non-enzymatic antioxidants [7-11]. This toxic phenomenon, called oxidative stress, results in stimulation of the process of membrane lipid peroxidation in the form of direct oxidation cell membrane thiol groups $(-\mathrm{SH})$ by reactive oxygen species with subsequent disintegration of their structure and increase of permeability, leading in consequence to the development of apoptosis and cell death [10-14].

The antioxidant barrier in an organism is formed by a non-homogeneous group of non-enzymatic compounds and antioxidant enzymes such as superoxide dismutase (SOD), copper-zinc superoxide dismutase ( $\mathrm{Cu}, \mathrm{Zn}$ SOD), manganese superoxide dismutase (Mn-SOD), catalase (CAT), glutathione peroxidase (GPx), glutathione reductase (GR), and glutathione S-transferase (GST) [1517].

The literature lacks papers dealing with the influence of the above-mentioned electromagnetic fields on the intensity of prooxidant processes, as well as on the activity of antioxidant enzymes in digestive system tissues. The aim of this study was to evaluate the impact of 50 $\mathrm{Hz}$ electromagnetic fields generated by high-voltage alternating electric current transmission lines, $900 \mathrm{MHz}$ electromagnetic fields emitted by mobile phones, and simultaneous exposure to those forms of electromagnetic fields on prooxidant/antioxidant balance in liver tissue of male rats. We analyzed the contents of markers of oxidative stress and membrane lipid peroxidation (total oxidant capacity (TOC) and malone dialdehyde (MDA), respectively) and the activity of the selected basic antioxidant enzymes superoxide dismutase, copper-zinc superoxide dismutase, manganese superoxide dismutase, catalase, and glutathione peroxidase, as well as examining the cell's ultrastructure in specimens from liver samples in an electron microscope.

\section{Experimental Procedures}

The experiment was performed on 40 male Wistar rats with a mean age of 10 weeks and mean initial body mass of $180 \pm 7.5 \mathrm{~g}$ before the experiment. For the duration of the experiment the animals were kept in special plastic cages, in optimal environmental conditions (stable humidity of air of $60 \%$ and $21^{\circ} \mathrm{C}$, retaining the 24-hour cycle of a 12-hour day phase in artificial light and a 12-hour night phase). The animals were provided with daily sanitaryhygienic service. They were fed with standard laboratory pellet food for rodents (Labofeed B) and had unlimited access to tap water.

All procedures involving animals were carried out in accordance with the Animals Scientific Procedures Act published by the U.S. National Institute of Health (1985) and EU Directive 2010/63/EU for animal experiments, and were accepted by the Local Ethical Commission for Experiments on Animals in Katowice (permission No. 65/2008).

The rats were randomly divided into four groups, consisting of 10 animals each.

Rats from the examined group (S) were exposed for 28 succeeding days to an electromagnetic field with physical parameters emitted by typical high-voltage alternat- 
ing electric current transmission lines, with frequency of $50 \mathrm{~Hz}$, intensity of $10 \mathrm{kV} / \mathrm{m}$, and magnetic induction of $4.3 \mathrm{pT}$, which was generated by a high-voltage test transformer between two round electrodes of experimental exposure system that were $50 \mathrm{~cm}$ from each other. The exposure lasted 22 hours a day (with a break between 08:00 and 10:00), and during exposure the animals were placed on an earthed electrode in a special plastic cage (10 animals per cage) that did not disturb the applied electromagnetic field and allowed for the possibility of free movement.

Rats from the examined group (M) were exposed for 28 succeeding days to an electromagnetic field with frequency of $900 \mathrm{MHz}$ generated by a Nokia 5110 mobile phone placed directly under the cage with animals, that was turned on every half hour for eight hours daily and emitted a signal for $15 \mathrm{~s}$, hence the total duration of dialed calls was four minutes per day. The mean value of power density of the electromagnetic field registered while initializing the connection was $85.3 \mu \mathrm{W} / \mathrm{m}^{2}$, and during the connection was $17.0 \mu \mathrm{W} / \mathrm{m}^{2}$. The average density of the electromagnetic field was calculated on the basis of 16 consecutive measurements of the field's density, recorded in five measuring points within the plastic cage by means of a TES-92 electromagnetic interference meter.

Rats from the examined group $(\mathrm{S}+\mathrm{M})$ were exposed for 28 succeeding days to simultaneous actions of a highvoltage $50 \mathrm{~Hz}$ electromagnetic field emitted by typical high-voltage alternating electric current transmission lines and a radio-frequency electromagnetic field generated by a mobile phone, with identical physical parameters and time distribution of exposure as in previous examined groups $\mathrm{S}$ and $\mathrm{M}$.

Rats from control group $\mathrm{K}$ were subjected for 28 succeeding days to sham-exposure, during which they were kept in environmental conditions identical to those of the examined animals (excluding the presence of electromagnetic fields).

After completion of the cycle of 28 daily exposures to electromagnetic fields or sham-exposures (control rats), the animals were starved by 24 hours and then anaesthetized using a mixture of xylazine (10 mg/kg i.p.) and ketamine $(100 \mathrm{mg} / \mathrm{kg}$ i.p.). Next, after surgically opening the chest by costotomy and collecting total amounts of blood (ca. $4 \mathrm{ml}$ ) from the left heart ventricle with use of $0.5 \times 30 \mathrm{~mm}$ injection needle connected to a syringe, the abdominal cavity was opened and liver samples were taken. In the homogenates prepared from the obtained samples, we measured the contents of oxidative stress markers (TOC and marker of membrane lipid peroxidation MDA, as well as the activity of the selected basic antioxidant enzymes $\mathrm{SOD}$, its isoenzymes $\mathrm{Cu}, \mathrm{Zn}-\mathrm{SOD}$ and Mn-SOD, CAT, and GPx).

In order to determine whether potential disturbances of the prooxidant/antioxidant balance are an effect of functional changes or structural lesions, in specimens prepared from liver tissue samples, we used an electron microscope to examine cellular membranes, intercellular junctions, mitochondria, smooth and rough endoplasmatic reticulum, lysosomes, and cell nuclei.

The contents of TOC in liver homogenates were determined by a method based on oxidation of $\mathrm{Fe}^{2+}$ to $\mathrm{Fe}^{3+}$ in an acidic environment with subsequent creation if colour complex, according to Erel [18], while the contents of MDA in liver homogenates were measured by the spectrofluorimetric method according to Ohkawa [19].

The activity of SOD in homogenates of liver tissue were determined by the method according to Oyanagui [20], which is fully specific for superoxide dismutase. Enzymatic activity has been expressed in nitrite units (NU) per $1 \mathrm{mg}$ of protein. One nitrite unit (NU) stands for the ability of reducing the generation of nitrite ions by $50 \%$, in reference to initial values, in the presence of SOD. The activity of the superoxide dismutase isoenzymes Mn$\mathrm{SOD}$ and $\mathrm{Cu}, \mathrm{Zn}-\mathrm{SOD}$ has been determined by means of the same methodology with the use of potassium cyanide as an inhibitor of the Mn-SOD isoenzyme and, as in the case of total activity of SOD, it was expressed in [NU/mg] of protein.

The activity of CAT in liver homogenates was determined by the kinetic method according to Aebi [21] and the activity of GPx in liver homogenates was measured using the spectrophotometric method according to Paglia and Valentine [22].

\section{Statistical Analysis}

The obtained results, presented as mean value \pm standard deviation (SD), underwent statistical analysis with the use of Statistica 7.1 PL software. The statistical estimation was performed on the basis of analysis of variance (ANOVA), after prior checking the homogeneity of variance by means of Levene's test and the normality of distribution in specific groups. If the homogeneity of variance was detected in Levene's test, single-factor parametric ANOVA (Student T-test) was used, whereas in the case of the occurrence of non-homogenous variance, the ANOVA Kruskal-Wallis test was applied. Each time, a comparison was made between results obtained in specific electromagnetic field-exposed groups and the control group. The assumed level of significance was $p<0.05$.

\section{Results}

The contents (mean value $\pm \mathrm{SD}$ ) of total protein in homogenates of liver tissue in electromagnetic fieldexposed rats from groups $\mathrm{S}, \mathrm{M}$, and $\mathrm{S}+\mathrm{M}$, as well as in sham-exposed rats from control group $\mathrm{K}$ are presented in Fig. 1.

In rats from group $\mathrm{S}+\mathrm{M}$, exposed simultaneously to both forms of electromagnetic field, the contents of total protein in homogenates of liver tissue was significantly higher in comparison with control group $\mathrm{K}$ $(18.62 \pm 1.69 \mathrm{mg} / \mathrm{ml}$ vs. $15.25 \pm 0.72 \mathrm{mg} / \mathrm{ml}, \mathrm{p}<0.001)$. In other groups ( $\mathrm{S}$ and $\mathrm{M}$ ) of electromagnetic field-exposed 


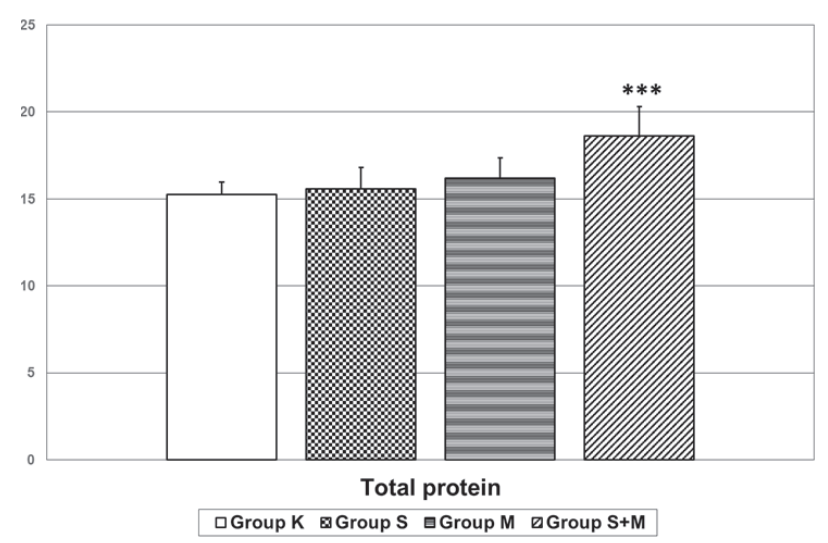

Fig. 1. The contents (mean value $\pm \mathrm{SD}$ ) of total protein $(\mathrm{mg} /$ $\mathrm{ml}$ ) in homogenates of liver tissue in rats exposed to a $50 \mathrm{~Hz}$ electromagnetic field generated by high-voltage alternating electric current transmission lines (group S), in rats exposed to a $900 \mathrm{MHz}$ electromagnetic field emitted by a mobile phone (group $\mathrm{M}$ ), in rats exposed simultaneously to both forms of electromagnetic field (group $\mathrm{S}+\mathrm{M}$ ), and in the control shamexposed rats (group $\mathrm{K}$ ), with statistical analysis. $* * * \mathrm{p}<0.001$

rats no significant differences of contents of total protein in homogenates of liver tissue were observed (as compared to control sham-exposed rats from group $\mathrm{K}$ ).

Fig. 2 presents the contents (mean value \pm SD) of markers of prooxidant processes (malone dialdehyde (MDA) and Total Oxidant Capacity (TOC)) in homogenates of liver tissue in electromagnetic field-exposed rats from groups $\mathrm{S}, \mathrm{M}$, and $\mathrm{S}+\mathrm{M}$, as well as in sham-exposed rats from control group $\mathrm{K}$.

In rats from group $\mathrm{S}$, exposed to the $50 \mathrm{~Hz}$ electromagnetic field generated by high-voltage alternating electric current transmission lines, no significant differences of the

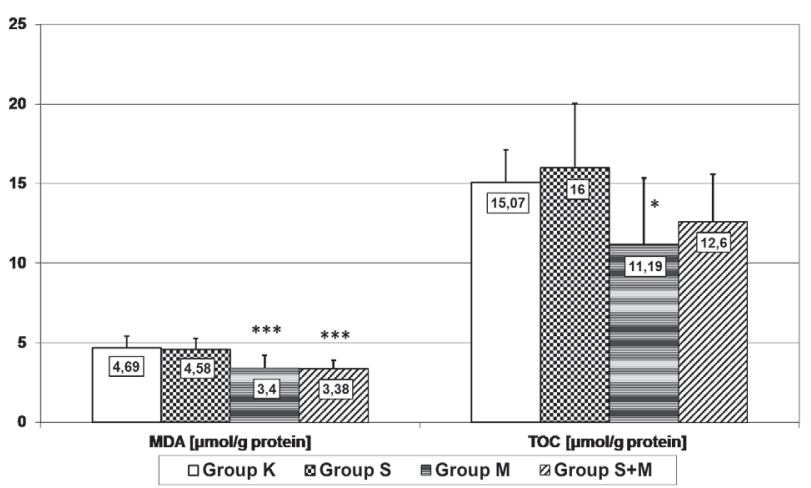

Fig. 2. The contents (mean value $\pm \mathrm{SD}$ ) of markers of oxidant processes: malone dialdehyde (MDA; $\mu \mathrm{mol} / \mathrm{g}$ protein) and total oxidant capacity (TOC; $\mu \mathrm{mol} / \mathrm{g}$ protein) in homogenates of liver tissue in rats exposed to a $50 \mathrm{~Hz}$ electromagnetic field generated by high-voltage alternating electric current transmission lines (group S), in rats exposed to a $900 \mathrm{MHz}$ electromagnetic field emitted by a mobile phone (group M), in rats exposed simultaneously to both forms of electromagnetic field (group $\mathrm{S}+\mathrm{M}$ ), and in the control sham-exposed rats (group K), with statistical analysis. ${ }^{*} \mathrm{p}<0.05, * * * \mathrm{p}<0.001$. contents of MDA and TOC in homogenates of liver tissue were observed, as compared to control sham-exposed rats from group $\mathrm{K}$.

In rats from group $\mathrm{M}$, exposed to $900 \mathrm{MHz}$ electromagnetic fields emitted by a mobile phone, the contents of MDA in homogenates of liver tissue were significantly lower in comparison with control group K $(3.38 \pm 0.53$ $\mu \mathrm{mol} / \mathrm{g}$ protein vs. $4.69 \pm 0.73 \mu \mathrm{mol} / \mathrm{g}$ protein, $\mathrm{p}<0.001)$, and the contents of TOC in homogenates of liver tissue were also significantly lower in comparison with control group K $(12.59 \pm 2.99 \mu \mathrm{mol} / \mathrm{g}$ protein vs. $15.07 \pm 2.06$ $\mu \mathrm{mol} / \mathrm{g}$ protein, $\mathrm{p}<0.001)$.

In rats from group $\mathrm{S}+\mathrm{M}$, exposed simultaneously to both forms of electromagnetic fields, the contents of MDA in homogenates of liver tissue were significantly lower in comparison with control group $\mathrm{K}(3.38 \pm 0.53 \mu \mathrm{mol} / \mathrm{g}$ protein vs. $4.69 \pm 0.73 \mu \mathrm{mol} / \mathrm{g}$ protein, $\mathrm{p}<0.001)$, whereas the contents of TOC in homogenates of liver tissue were also distinctly lower in comparison with control group $\mathrm{K}$ $(12.59 \pm 2.99 \mu \mathrm{mol} / \mathrm{g}$ protein vs. $15.07 \pm 2.06 \mu \mathrm{mol} / \mathrm{g}$ protein, $\mathrm{p}=0.116$ ), but the observed difference was not statistically significant.

Fig. 3 presents the activity (mean value \pm SD) of selected basic antioxidant enzymes (superoxide dismutase (SOD), copper-zinc superoxide dismutase (Cu, Zn-SOD), manganese superoxide dismutase (Mn-SOD), catalase (CAT) and glutathione peroxidase (GPx)) in homogenates of liver tissue in electromagnetic field-exposed rats from groups $\mathrm{S}, \mathrm{M}$, and $\mathrm{S}+\mathrm{M}$, as well as in sham-exposed rats from control group $\mathrm{K}$.

In rats from group $\mathrm{S}$ exposed to the $50 \mathrm{~Hz}$ electromagnetic field generated by high-voltage alternating electric current transmission lines, no significant

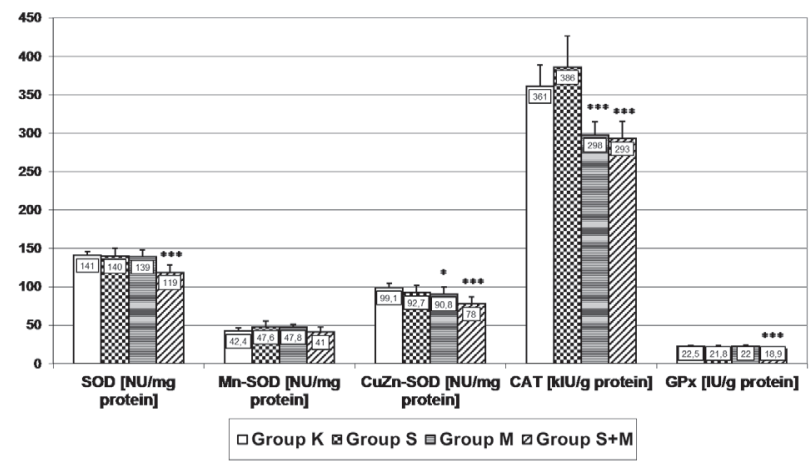

Fig. 3. The activity (mean value $\pm \mathrm{SD}$ ) of antioxidant enzymes: superoxide dismutase (SOD; NU/mg protein), manganesedependent superoxide dismutase (Mn-SOD; NU/mg protein), cuprum and zinc-dependent superoxide dismutase (Cu,Zn-SOD; $\mathrm{NU} / \mathrm{mg}$ protein), catalase (CAT; $\mathrm{kIU} / \mathrm{g}$ protein), and glutathione peroxidase (GPx; IU/g protein) in homogenates of liver tissue in rats exposed to a $50 \mathrm{~Hz}$ electromagnetic field generated by highvoltage alternating electric current transmission lines (group S), in rats exposed to a $900 \mathrm{MHz}$ electromagnetic field emitted by a mobile phone (group M), in rats exposed simultaneously to both forms of electromagnetic field (group $\mathrm{S}+\mathrm{M}$ ), and in the control sham-exposed rats (group K), with statistical analysis. * $\mathrm{p}<0.05$, $* * * \mathrm{p}<0.001$. 
differences of the activity of total SOD, Cu, Zn-SOD, MnSOD, CAT, and GPx in homogenates of liver tissue were observed, as compared to control sham-exposed rats from group $\mathrm{K}$.

In rats from group $\mathrm{M}$, exposed to the electromagnetic field emitted by mobile phones, the activities of $\mathrm{Cu}, \mathrm{Zn}$ SOD and CAT in homogenates of liver tissue were significantly lower in comparison with control group K $(90.78 \pm 8.76 \mathrm{NU} / \mathrm{mg}$ protein vs. $99.05 \pm 5.74 \mathrm{NU} / \mathrm{mg}$ protein, $\mathrm{p}<0.032$, and $297.98 \pm 16.65 \mathrm{kIU} / \mathrm{g}$ protein vs. $360.92 \pm 27.27 \mathrm{kIU} / \mathrm{g}$ protein, $\mathrm{p}<0.001$, respectively), while the activity of total SOD, Mn-SOD, and GPx in homogenates of liver tissue did not differ significantly in comparison with control group $\mathrm{K}$.

In rats from group $\mathrm{S}+\mathrm{M}$, exposed simultaneously to both forms of electromagnetic fields, the activities of total $\mathrm{SOD}, \mathrm{Cu}, \mathrm{Zn}-\mathrm{SOD}, \mathrm{CAT}$, and GPx in homogenates of liver tissue were significantly lower in comparison with control group K $(119.06 \pm 9.18 \mathrm{NU} / \mathrm{mg}$ protein vs. $141.42 \pm 5.40$ $\mathrm{NU} / \mathrm{mg}$ protein, $\mathrm{p}<0.001 ; 78.04 \pm 9.10 \mathrm{NU} / \mathrm{mg}$ protein vs. $99.05 \pm 5.74 \mathrm{NU} / \mathrm{mg}$ protein, $\mathrm{p}<0.001 ; 292.92 \pm 22.65$ $\mathrm{kIU} / \mathrm{g}$ protein vs. $360.92 \pm 27.27 \mathrm{kIU} / \mathrm{g}$ protein, $\mathrm{p}<0.001$, and $18.95 \pm 1.93 \mathrm{IU} / \mathrm{g}$ protein vs. $22.52 \pm 1.35 \mathrm{IU} / \mathrm{g}$ protein, $\mathrm{p}<0.001$, respectively), while the activity of Mn-SOD in homogenates of liver tissue did not differ significantly in comparison with control group $\mathrm{K}$.

The results of examining liver specimens using an electron microscope, comprising cellular membranes, intercellular junctions, mitochondria, smooth and rough endoplasmatic reticulum, lysosomes, and cell nuclei revealed no structural differences in any of the electromagnetic field-exposed groups of rats, in comparison with the control sham-exposed group.

\section{Discussion of Results}

In recent years the human population has become permanently exposed to electromagnetic fields with industrial frequency generated by high-voltage alternating electric current transmission lines and to radiofrequency electromagnetic fields emitted by mobile telephony systems, both in living places and in occupational conditions. This is why the impact of those electromagnetic fields upon living organisms and its potential health consequences captures a lot of attention and generates much controversy [23-26]. Studies conducted so far have focused mainly on the reactions occurring in the central nervous system and the potential carcinogenic effects of those electromagnetic fields, in both humans and animals. The available results of those studies are not unequivocal, which may be due to different methodology of exposure and physical parameters of applied electromagnetic fields in the studies reported [4, 27-31].

However, exposure to electromagnetic fields may also affect other functions of the human organism, including oxidative processes, resulting in disturbances of prooxidant/antioxidant balance in cells (so-called oxidative stress). Oxidative stress occurs in a situation when an excessive amount of generated reactive oxygen species (ROS) cannot be neutralized by an inefficient antioxidant defense system, resulting in an inability to detoxify the reactive intermediate products, which causes in consequence oxidative lesions of cell constituents, especially cellular membranes [32-33]. It is assumed that electromagnetic fields may affect proxidant/antioxidant balance in cells directly by impacting ROS generation and the activity of antioxidant enzymes or by systemic effect.

Available literature lacks experimental data regarding the impact of long-term exposure to both of the abovementioned forms of electromagnetic fields on oxidative processes taking place in particular structures of the alimentary tract, including liver, especially in the case of combined simultaneous action of those fields.

This is why an experimental animal model was designed for the present study to simulate a common situation in which energy sector workers or inhabitants living in the vicinity of high-voltage transmission lines regularly use mobile phones. In this model adult male rats were subjected to relatively long-term (28 days) exposure to a 50 $\mathrm{Hz}$ electromagnetic field with typical physical parameters observed in the corridor of high-voltage transmission lines (electric field intensity of $10 \mathrm{kV} / \mathrm{m}$ and magnetic induction of $4.3 \mathrm{pT}$ ) lasting 22 hours daily, to $900 \mathrm{MHz}$ electromagnetic field with power density of the electromagnetic field $17.0-85.3 \mu \mathrm{W} / \mathrm{m}^{2}$, emitted by a typical mobile phone 16 times a day with total time of daily exposure lasting four minutes, and to simultaneous exposure to those forms of electromagnetic field.

Taking into account the fact that the determination of the impact of electromagnetic fields upon oxidative stress in tissues is a complex process, including the assessment of the consequences of excessive generation of ROS in the form of an increase of tissue oxidant capacity and intensity of lipid peroxidation, as well as the activity of an antioxidant defense system in presented experimental model, similar to most experimental studies, the evaluation of impact of applied electromagnetic fields on prooxidant/ antioxidant balance was performed by means of analysis of the contents of markers of oxidative stress and membrane lipid peroxidation - total oxidant capacity (TOC) and malone dialdehyde (MDA), respectively - and the activity of the selected basic antioxidant enzymes superoxide dismutase, copper-zinc superoxide dismutase, manganese superoxide dismutase, and catalase and glutathione peroxidase in homogenates of liver tissue, as well as the examination of a cell's ultrastructure in specimens from liver samples in an electron microscope.

In the present study we observed a lack of significant changes in the contents of both markers of prooxidant processes and in the activity of all antioxidant enzymes in liver homogenates in rats from group S, as compared to control sham-exposed group $\mathrm{K}$, indicating that a fourweek exposure to a high-voltage $50 \mathrm{~Hz}$ electromagnetic field does not affect prooxidant/antioxidant balance in liver tissue.

In turn, a significant decrease in the contents of both markers of prooxidant processes with accompanying 
significant decrease in the activity of $\mathrm{Cu}, \mathrm{Zn}-\mathrm{SOD}$ and CAT (in group $\mathrm{M}$ ) and in the activity of total SOD, $\mathrm{Cu}, \mathrm{Zn}$ SOD, CAT and GPx (in group S+M) in liver homogenates indicates that exposure to a $900 \mathrm{MHz}$ electromagnetic field emitted by mobile phone and simultaneous exposure to both forms of electromagnetic fields cause disturbances of prooxidant/antioxidant balance in liver tissue of exposed animals.

The potential mechanisms of observed effects could be related to the inhibition of oxidative processes in liver tissue by electromagnetic field with subsequent compensatory inhibition of antioxidant enzyme activity or - what is more probably being taken into account as shown by the literature data presented below - to extremely efficient action of enzymatic antioxidant system in liver cells, leading to excessive neutralization of previously stimulated oxidative stress.

So far, only a few experimental studies in attainable literature concern the influence of electromagnetic fields with industrial frequency of $50 \mathrm{~Hz}$ generated by alternating electric current transmission lines and radiofrequency electromagnetic fields emitted by mobile phones on the oxidative status of liver tissue.

The results of [34] confirmed that exposure of guinea pigs to a $50 \mathrm{~Hz}$ electromagnetic field with intensity of $0.3-1.8 \mathrm{kV} / \mathrm{m}$ for $1,3,5,7$, and 10 days caused an increase in the activity of SOD and in the contents of TBARS lipid peroxides in liver tissue of exposed animals, and intensification of observed changes depended on the intensity of electromagnetic field and time of exposure. In the next study of the same team, the exposure of guinea pigs to an electromagnetic field with higher intensity of $12 \mathrm{kV} / \mathrm{m}$ caused a significant increase in the contents of MDA and a significant decrease in the activity of SOD, GPx, and myeloperoxidase (MPO) in liver tissue of exposed animals [35]. On the other hand, exposure of rats to a $50 \mathrm{~Hz}$ electromagnetic field with an intensity of $17.5 \mathrm{kV} / \mathrm{m}, 15$ minutes per day for seven days did not change significantly the concentration of MDA and the activity of antioxidant system in plasma of exposed animals [36].

The exposure of guinea pigs to an $1,800 \mathrm{MHz}$ electromagnetic field emitted by GSM mobile communications systems 10-20 minutes per day for seven days caused intensification of oxidative stress in liver tissue in the form of significant increase in the contents of MDA and total nitric oxide (NO) and significant decreases in the activities of SOD, MPO, and GPx in liver tissue [37]. In another experimental study exposure of male albino rats to a $900 \mathrm{MHz}$ electromagnetic field one hour per day for 60 days caused a significant increase in the contents of MDA and a significant decrease in the level of total antioxidant capacity (TAC) in liver tissue of exposed animals. The observed alterations were transitory and they disappeared 30 days after withdrawal of exposure [38]. In turn, exposure of rats to electromagnetic fields emitted by a GSM mobile communication system caused a significant decrease in the activities of SOD and CAT, as well as in the concentration of reduced glutathione $(\mathrm{GSH})$ in plasma of exposed animals, and the effect of acute exposure was stronger than those of fractionated exposure, provided 15 minutes per day for four days [39].

Generally, the results of other authors confirm the decrease in activity of antioxidant enzymes during exposure to analyzed electromagnetic fields, but in most of the studies an increase in the contents of markers of oxidative stress and lipid membrane peroxidation was observed. It might be due to different physical parameters of applied electromagnetic fields and different methodology of exposure, especially related to duration of the experiment. It seems that the longer time of adaptation to impact of radio-frequency electromagnetic field, as in the present experiment, with a relatively short time of daily exposures, enables more efficient action of enzymatic antioxidant systems, resulting in final neutralization of a previously generated increased amount of oxidative stress products, and thus a decrease in antioxidant enzyme activities could be a result of their excessive use for restoring prooxidant/ antioxidant balance on a new lower level.

Moreover, the lack of any structural changes in liver cells visible in an electron microscope and the disappearance of disturbances of prooxidant/antioxidant balance after withdrawal of exposure observed in [38] indicate the functional character of the observed alterations.

\section{Conclusions}

Four-week exposure to a high-voltage $50 \mathrm{~Hz}$ electromagnetic field does not affect the prooxidant/ antioxidant balance in the liver tissue of rats, while exposure to a radiofrequency electromagnetic field emitted by mobile phone and simultaneous exposure to both forms of electromagnetic field significantly inhibits the intensity of prooxidant processes and decreases the activity of most antioxidant enzymes in liver tissue, especially in cases of simultaneous action of both fields, probably due to their excessive use for restoring prooxidant/antioxidant balance, without causing any structural changes in liver cells visible in an electron microscope.

\section{Acknowledgments}

This project was supported by grant No. N N511 351737 from the Polish Ministry for Science and Higher Education.

\section{References}

1. BEHARI J. Biological responses of mobile phone frequency exposure. Indian J. Exp. Biol. 48 (10), 959, 2010.

2. CHAVDOULA E.D., PANAGOPOULOS D.J., MARGARITIS L.H. Comparison of biological effects between continuous and intermittent exposure to GSM-900$\mathrm{MHz}$ mobile phone radiation: Detection of apoptotic celldeath features. Mutat. Res. 700 (1-2), 51, 2010. 
3. SINGH H.P., SHARMA V.P., BATISH D.R., KOHLI R.K. Cell phone electromagnetic field radiations affect rhizogenesis through impairment of biochemical processes. Environ. Monit. Assess. 184 (4), 1813, 2012.

4. SWERDLOW A.J., FEYCHTING M., GREEN A.C. International Commission for Non-Ionizing Radiation Protection Standing Committee on Epidemiology: Mobile phones, brain tumors, and the interphone study: where are we now? Environ. Health Perspect. 119 (11), 1534, 2011.

5. SMITH P., KUSTER N., EBERT S., CHEVALIER HJ. GSM and DCS wireless communication signals: combined chronic toxicity/carcinogenicity study in the Wistar rat. Radiat. Res. 168 (4), 480, 2007.

6. LAI J., ZHANG Y., ZHANG J. Effects of 100- $\mu$ T extremely low frequency electromagnetic fields exposure on hematograms and blood chemistry in rats. J. Radiat. Res. 57 (1), 16, 2016.

7. AKDAG M.Z., DASDAG S., ULUKAYA E. Effects of extremely low-frequency magnetic field on caspase activities and oxidative stress values in rat brain. Biol. Trace Elem. Res. 138 (1-3), 238, 2010.

8. CIEŚLAR G., MAŁYSZEK-TUMIDAJEWICZ J., SOWA P. SIEROŃ A. Impact of static electric field on prooxidantantioxidant balance in rats. COMPEL. 31 (4), 1212, 2012.

9. DEL CARRATORE R., MORICHETTI E., DELLA CROCE C., BRONZETTI G. Effect of magnetic fields on rodent monooxygenase enzymes. Bioelectromagnetics. 16 (5), 324, 1995.

10. WOLF F.I., TORSELLO A., TEDESCO B., FASANELLA S., BONINSEGNA A., D'ASCENZO M., GRASSI C., AZZENA G.B., CITTADINI A. 50-Hz extremely low frequency electromagnetic fields enhance cell proliferation and DNA damage: Possible involvement of a redox mechanism. Biochim. Biophys. Acta. 1743 (1-2), 120, 2005.

11. OZGUR E., SAHIN D., TOMRUK A. The effects of Nacetylcysteine and epigallocatechin-3-gallate on liver tissue protein oxidation and antioxidant enzyme levels after the exposure to radiofrequency radiation. Int. J. Radiat. Biol. 91 (2), 187, 2015.

12. CADENAS E., Davies K. Mitochondrial free radical generation, oxidative stress and aging. Free Radic. Biol. Med. 29 (3-4), 222, 2000.

13. ITOH K., ISHII T., WAKABAYASHI N., YAMAMOTO M. Regulatory mechanisms of cellular response to oxidative stress. Free Radic. Res. 31 (4), 319, 1999.

14. VALKO M., LEIBFRITZ D., MONCOL J. Free radicals and antioxidants in normal physiological functions and human disease. Int. J. Biochem. Cell Biol. 39, 44, 2007.

15. BURTON G.J., JAUNIAUX E. Oxidative stress. Best Pract. Res. Clin. Obstet. Gynaecol. 25 (3), 287, 2011.

16. CZAJKA A. Reactive oxygen species and mechanisms of body protection. Nowiny Lek. 75 (6), 582, 2006 [In Polish].

17. GALECKA E., JACEWICZ R., MROWICKA M. FLORKOWSKI A, GAŁECKI P. Antioxidative enzymes structure, properties, functions. Pol. Merkur. Lek. 25 (147), 266, 2008 [In Polish].

18. EREL O. A new automated colorimetric method for measuring total oxidant status. Clin. Biochem. 38 (12), 1103, 2005.

19. OHKAWA H., OHISHI N., YAGI K. Assay for lipid peroxides in animal tissues by thiobarbituric acid reaction. Anal. Biochem., 95, 351, 1979.

20. OYANAGUI Y. Reevaluation of assay methods and establishment of kit for superoxide dismutase activity. Anal. Biochem. 142, 290, 1984.

21. AEBI H. Catalase in vitro. Methods Enzymol. 105, 121, 1984.
22. PAGLIA D.E., VALENTINE W.N. Studies on the quantitative and qualitative characterization of erythrocyte glutathione peroxidase. J. Lab. Clin. Med. 70, 158, 1967.

23. HIDISOGLU E., KANTAR-GOK D. 2100-MHz electromagnetic fields have different effects on visual evoked potentials and oxidant/antioxidant status depending on exposure duration. Brain Res. 15, 31, 2016.

24. NERSESOVA L.S., PETROSIAN M.S., GAZARIANTS M.G. Effect of low-intensity $900 \mathrm{MHz}$ frequency electromagnetic radiation on rat liver and blood serum enzyme activities. Radiats Biol. Radioecol. 54 (5), 522, 2014.

25. PANAGOPOULOS D.J., MARGARITIS L.H. The effect of exposure duration on the biological activity of mobile telephony radiation. Mutat. Res. 699 (1-2), 17, 2010.

26. RÓÓSLI M., HUG K. Wireless communication fields and non-specific symptoms of ill health: a literature review. Wien Med. Wochenschr. 161 (9-10), 240, 2011.

27. LI B.L., LI W., BI J.Q. Effect of long-term pulsed electromagnetic field exposure on hepatic and immunologic functions of rats.Wien Klin. Wochenschr. 127 (23-24), 959, 2015.

28. SÓDERQVIST F., CARLBERG M., HANSOON M. Childhood brain tumor risk and its association with wireless phones: a commentary. Environ. Health. 10, 106, 2011.

29. TAKEBAYASHI T., VARSIER N., KIKUCHI Y. Mobile phone use, exposure to radiofrequency electromagnetic field, and brain tumor: a case-control study. Br. J. Cancer. 98 (3), 652, 2008.

30. BAYAZIT V., BAYRAM B., PALA Z., ATAN O. Evaluation of carcinogenic effects of electromagnetic fields (EMF). Bosn. J. Basic Med. Sci. 10 (3), 245, 2010.

31. PARAZZINI M., SIBELLA F., LUTMAN M.E. Effects of UMTS cellular phones on human hearing: results of the European project EMFnEAR. Radiat. Res. 172 (2), 244, 2009.

32. SEIFIRAD S., FARZAMPOUR S., NOURBAHSK M. Effects of extremely low frequency electromagnetic fields on paraoxonase serum activity and lipid peroxidation metabolites in rat. J. Diabetes Metab. Disord. 13 (1), 85, 2014.

33. WIEDEMANN P., SCHUTZ H. Children's health and RF EMF exposure. Views from a risk assessment and risk communication perspective. Wien Med. Wochenschr. 161 (9-10), 226, 2011.

34. GÜLER G., SEYHAN N., ARICIOGLU A. Effects of static and $50 \mathrm{~Hz}$ alternating electric fields on superoxide dismutase activity and TBARS levels in guinea pigs. Gen. Physiol. Biophys. 25 (2), 177, 2006.

35. GÜLER G., TURKOZER Z., TOMRUK A., SEYHAN $\mathrm{N}$. The protective effects of $\mathrm{N}$-acetyl-L-cysteine and epigallocatechin-3-gallate on electric field-induced hepatic oxidative stress. Int. J. Radiat. Biol. 84 (8), 669, 2008.

36. HARAKAWAS., INOUEN., HORI T, TOCHIO K., KARIYA T., TAKAHASHI K., DOGE F., SUZUKI H., NAGASAWA $\mathrm{H}$. Effects of a $50 \mathrm{~Hz}$ electric field on plasma lipid peroxide level and antioxidant activity in rats. Bioelectromagnetics. 26 (7), 589, 2005.

37. OZGUR E., GULER G., SEYHAN N. Mobile phone radiation-induced free radical damage in the liver is inhibited by the antioxidants $\mathrm{N}$-acetyl cysteine and epigallocatechingallate. Int. J. Radiat. Biol. 86 (11), 935, 2010.

38. ELHAG M.A., NABIL G.M., ATTIA A.M. Effects of electromagnetic field produced by mobile phones on the oxidant and antioxidant status of rats. Pak. J. Biol. Sci. 10 (23), 4271, 2010.

39. RAGY M.M. Effect of exposure and withdrawal of 900-MHz-electromagnetic waves on brain, kidney and liver oxidative stress and some biochemical parameters in male rats. Electromagn. Biol. Med. 34 (4), 279, 2015. 
